\title{
Medical students protest perks from drug companies
}

Jake Donaldson, a third-year medical student at the University of Washington, has lately been offered a few free things: a couple of textbooks left in his mailbox, pens and lunches at the medical center-all courtesy of a pharmaceutical company.

Drug companies in 2002 adopted new guidelines to cut back on expensive meals and other lavish perks for doctors. They instead began pitching their products over modest lunches in doctors' offices and hospitals, including those where medical students learn. Whether accepting small gifts can influence behavior is a much debated matter that has thus far focused primarily on doctors.

But Donaldson and his fellow students say the gifts are a threat to students' integrity.

In May, they drew up a petition — which more than half of the first- and second-year students have since signed - calling on the university to ban representatives of pharmaceutical companies from campus, prohibit students from accepting gifts and require full financial disclosure from guest speakers.

"The students really want to be sure their education isn't biased by pharmaceutical companies," says Thomas Norris, vice dean for academic affairs. Norris says the administration is working with students to develop a policy that should be finalized later this year.

In 2005, only 10 of the 126 medical schools in the US had such policies in place, but the number is rising. In February, Yale University

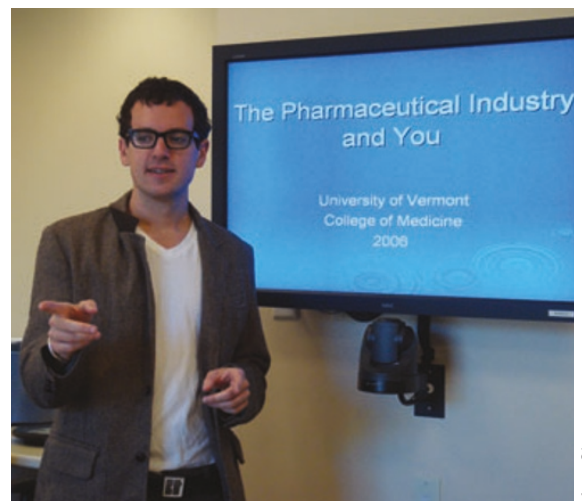

No free lunch: Drug makers' gifts can bias students, warns University of Vermont medical student Justin Sanders.

School of Medicine banned all gifts and oncampus meals from drug companies, followed in July by the University of Pennsylvania. The University of Vermont and the University of New Mexico are crafting guidelines.

“A good medical school shouldn't expose students to doctors receiving gifts for four years," says Robert Alpern, dean of Yale's medical school. Otherwise, he says, "they come to accept it as the norm."

At least one drug company, Pfizer, says promotions are aimed at doctors, not students. "When content is delivered in a medical institution such as a teaching hospital, students are exposed," says spokesperson Alison Lehanski.

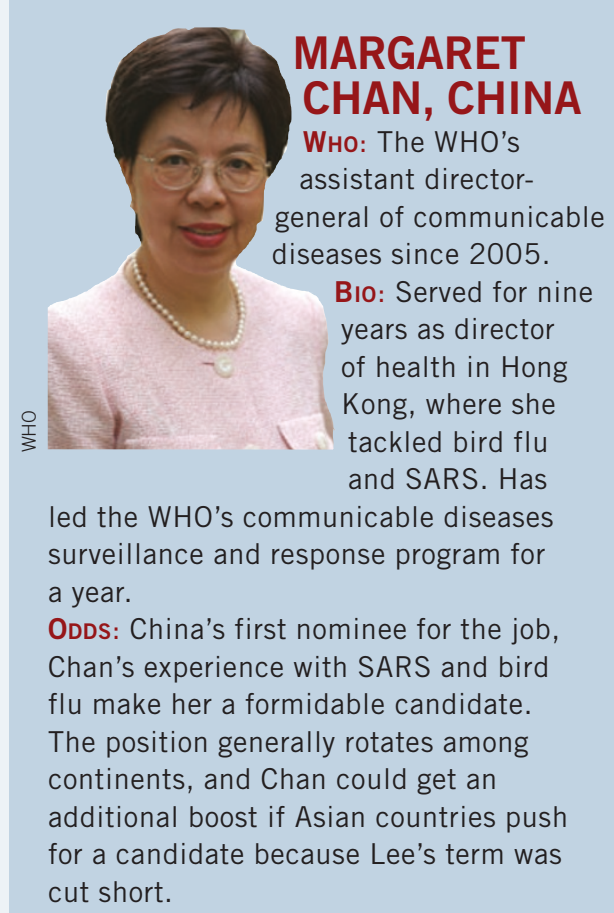

Still, students, like doctors, are susceptible to the industry's multibillion dollar marketing machine, says Frederick Sierles, a psychiatry professor at Rosalind Franklin University in Chicago. In a study of 826 third-year students at eight medical schools, Sierles found that students interact with drug companies about once a week, and tend to view gifts and activities sponsored by drug companies as valuable (JAMA 294, 1034-1042; 2005).

The American Medical Student Association's voluntary guidelines recommend that doctors, residents and students not accept promotional gifts. The association in 2002 launched the PharmFree campaign to educate students about the influence of drug companies.

"Medical students can quickly feel entitled to the perks pharmaceutical companies shower doctors and students with, and think they won't be biased," says Justin Sanders, chair of PharmFree and a student at the University of Vermont.

Students might be more skeptical of drug companies if medical schools address the issue formally, says Sierles. But a greater challenge, he says, will be to convince the students' mentors to stop accepting gifts.

"As long as physicians accept gifts and deny it's affecting them and students see this in their role models," he says, "we aren't going to see a radical shift."

Alisa Opar, New York

\section{JULIO FRENK, MEXICO}

Who: Mexico's minister of health since 2000. Bı: Is credited with implementing reforms to bring health coverage to Mexico's uninsured

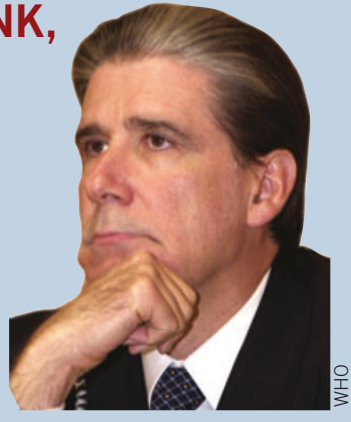
millions. As a senior WHO official from 1998 to 2000 , analyzed health situations and trends. ODDS: Frenk made the first cut in the 2003 race but lost to Lee, and is making a big push for the position this time around. He could edge out Omi and Chan with his depth of experience, or if voters follow the unwritten rule of rotating the top post among continents: of the last four directorgenerals, two have been Asian and two European. 


\section{Controlling immune response may cut bird flu death rate}

Avian influenza kills so many of its human victims because it replicates profusely and overstimulates the immune system: those findings, from the most extensive analysis of those infected, suggest that drugs to calm the immune system might help when standard antiviral treatment is unavailable or given too late.

Since 2003, more than 240 people have been diagnosed with $\mathrm{H} 5 \mathrm{~N} 1$ infections, and more than 140 of them have died. But there has been little information about how the virus ravages the body because many individuals are treated in rural or ill-equipped hospitals and too few samples have been collected. Autopsy tissue has also been hard to come by because of cultural taboos.

Vietnamese researchers collected and analyzed samples from 18 individuals infected in 2004 and 2005, 13 of whom later died. The researchers, led by Menno de Jong of the Oxford University Clinical Research Unit in Ho Chi Minh City, took blood, nose and throat samples, typically about six days into an infection, and compared them with those from individuals infected with $\mathrm{H} 3 \mathrm{~N} 2$ or H1N1 human flu strains.

The team found that $\mathrm{H} 5 \mathrm{~N} 1$ multiplies to levels up to hundreds of times higher than those of the human strains. The virus appears to prefer the lower respiratory tract, rather than the nose and throat favored by regular flu viruses. The team also detected viral RNA in the blood of patients who died, suggesting that it reached particularly high levels in these people (Nat. Med. 12, 12031207; 2006).

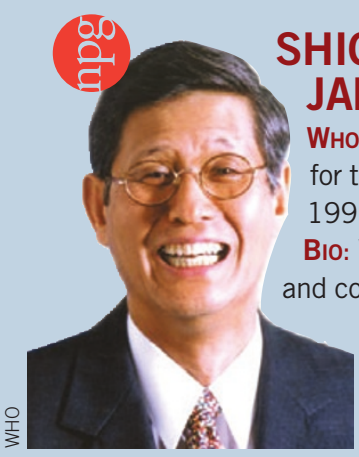

SHIGERU OMI, JAPAN

WHO: WHO's regional director for the Western Pacific since 1999.

Bıo: Worked on immunization and communicable diseases at the $\mathrm{WHO}$ and has extensive experience battling bird flu and SARS.

ODDS: A leading contender, Omi also

brings extensive experience with SARS and bird flu to the job. Though Asian countries might expect to claim the winner, fierce competition between China and Japan could knock Omi and Chan out of the race early on.

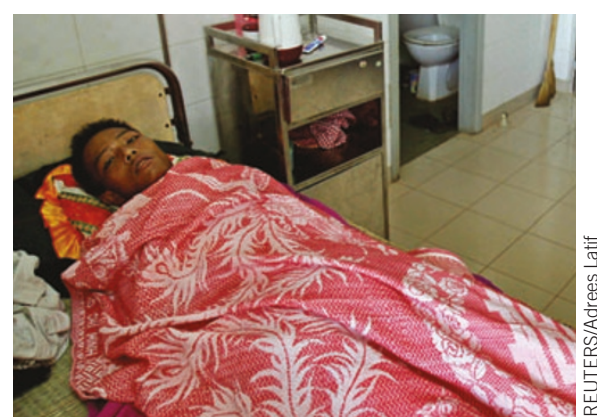

Rare find: Most bird flu victims in Vietnam are treated in rural or ill-equipped hospitals, making samples hard to collect.

"It's really going to be a landmark paper in describing what happens when humans are infected with avian influenza," says Peter Openshaw, an Imperial College London expert in immune response to respiratory infections.

The immune systems of those infected with H5N1 show hallmarks of intense activation. The researchers found high levels of several cytokines and chemokines in blood, particularly in patients who died, and a marked drop in infectionfighting white blood cells, or lymphocytes.

This uncontrolled outpouring of molecules, dubbed a 'cytokine storm,' can be triggered by toxins and bacterial infection, and is thought to eventually lead to the failure of lungs or other organs.

Researchers have previously suspected that avian flu can trigger a cytokine storm, which is also thought to have been important in severe acute respiratory syndrome and in the 1918 flu pandemic. But for $\mathrm{H} 5 \mathrm{~N} 1$, this is "the first time there is real data to support that concept," Openshaw says.

It is possible that the virus triggers this reaction because it replicates so fast, or because it makes proteins that aggressively stimulate the human immune system.

The study may explain why Tamiflu (oseltamivir), a drug that blocks viral replication, has so far saved few lives. The inflammatory response might have spun out of control by the time those infected began treatment, underscoring the need for early diagnosis and treatment.

It also suggests that drugs that quell the immune response might cut the death rate. Some doctors have already tried using steroids, which broadly suppress the immune system, but those drugs have not shown a clear benefit. Medicines that instead act on specific molecules - such as the anti-tumor necrosis factor therapy used for rheumatoid arthritismight be more effective.

De Jong says researchers need to collect more samples to test, for example, whether genetic makeup makes some people particularly susceptible. "It's too bad we haven't learned more," de Jong says. "If samples had been collected from all those patients, we would be a lot further in understanding this disease."

Helen Pearson, New York

\section{PEKKA PUSKA FINLAND \\ A,}

WHO: Director of Finland's National Public Health Institute since 2003.

Bıo: An expert in chronic diseases and head of the WHO's

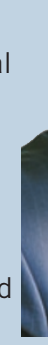

noncommunicable

disease prevention program from 2001 to 2003.

ODDs: Puska's expertise in running a major health agency and pioneering public health programs makes him a candidate to watch.

\section{PASCOAL MOCUMBI, MOZAMBIQUE}

Wн: High representative of the European and Developing Countries Clinical Trials Partnership since 2004. Bıo: Prime minister of Mozambique from 1994 to 2004; a trained clinician, he works to accelerate drugs for malaria, HIV/AIDS and tuberculosis.

OdDs: Mocumbi's active role in global health initiatives earned him a place on the WHO director-general shortlist in 2003. His experience and position as the lone African nominee make him a strong candidate, but at 65 , his age could work against him.

\section{OTHERS IN THE RUNNING}

Kazem Behbehani, Kuwait, special envoy to the WHO director general since 2005

David Gunnarsson, permanent secretary of Iceland's health and social security ministry

Nay Htun, Myanmar, former UN assistant secretary general
Karam Karam, former Lebanese health minister

Bernard Kouchner, France, founder of Médecins Sans Frontières (Doctors Without Borders)

Alfredo Palacio, interim president of Ecuador and surgeon.

Elena Salgado, Spain's health minister

Tomris Türmen, Turkey, WHO's executive director of family and community health 